\title{
Combined CD and DGD Monitoring Based on Data-Aided Channel Estimation
}

\author{
Pittalà, Fabio; Hauske, Fabian N.; Ye, Yabin; Guerrero Gonzalez, Neil; Tafur Monroy, Idelfonso
}

Published in:

Proceedings of Signal Processing in Photonic Communications (SPPCom)

Publication date:

2011

Document Version

Publisher's PDF, also known as Version of record

Link back to DTU Orbit

Citation (APA):

Pittalà, F., Hauske, F. N., Ye, Y., Guerrero Gonzalez, N., \& Tafur Monroy, I. (2011). Combined CD and DGD Monitoring Based on Data-Aided Channel Estimation. In Proceedings of Signal Processing in Photonic Communications (SPPCom) (pp. SPTuC3). Optical Society of America.

http://www.osa.org/meetings/topical_meetings/sppcom/default.aspx

\section{General rights}

Copyright and moral rights for the publications made accessible in the public portal are retained by the authors and/or other copyright owners and it is a condition of accessing publications that users recognise and abide by the legal requirements associated with these rights.

- Users may download and print one copy of any publication from the public portal for the purpose of private study or research.

- You may not further distribute the material or use it for any profit-making activity or commercial gain

- You may freely distribute the URL identifying the publication in the public portal 


\title{
Combined CD and DGD Monitoring Based on Data-Aided Channel Estimation
}

Fabio Pittalà $^{1,2}$, Fabian N. Hauske ${ }^{1}$, Yabin Ye ${ }^{1}$, Neil G. Gonzalez ${ }^{2}$, Idelfonso T. Monroy ${ }^{2}$

1: European Research Center, Huawei Technlogies Duesseldorf GmbH, Riesstrasse 25, D-80992 Munich, Germany, 2: DTU Fotonik, Technical University of Denmark, Ørsteds Plads 343, DK-2800 Kgs. Lyngby, Denmark.

E-mail: fabio.pittala@huawei.com

\begin{abstract}
By use of a training sequence, fast and robust CD and DGD estimation is demonstrated for a $112 \mathrm{Gbit} / \mathrm{s}$ PDM-QPSK system over a wide range of combined channel impairments. OCIS codes: (060.1660) Coherent communications; (060.2330) Fiber optics communications
\end{abstract}

\section{Introduction}

Coherent detection receivers with digital equalization allow full compensation of all linear channel impairments of a linear or weakly nonlinear optical fiber channel. A wide range of approaches is used for optical channel estimation. Non-data-aided (NDA) channel acquisition based on gradient algorithms for time-domain (TD) filters is widely considered [1], whereas data-aided (DA) channel estimation offers faster convergence at the cost of slight bandwidth efficiency degradation due to the insertion of regular training patterns in slowly time-varying channels. In addition, DA channel acquisition is applicable to frequency-domain (FD) filters [2]. Once the filter transfer function W( $f)$ has been obtained, powerful parameter estimation for optical performance monitoring (OPM) can be applied [3].

In the following, chromatic dispersion (CD) and differential group delay (DGD) estimation based on DA channel estimation for FD filters is demonstrated with different training sequences.

\section{Data-aided channel estimation based on CAZAC training sequences}

Prior to parameter estimation the channel transfer function $\mathbf{H}(f)$ has to be obtained. In general, the training sequence for the $2 \times 2$ multi-input multi-output (MIMO) system can be composed of four independent blocks C1, C2, C3 and C4, which might be (optionally) framed by guard intervals (GI) [2]. The training sequence (TS) is repeated regularly, as shown in Fig. 1. We choose constant-amplitude zero-autocorrelation (CAZAC) sequences, which provide optimum framing synchronization. With the aid of the received spectra $\mathrm{R}(\mathrm{C} 1, \mathrm{C} 2, \mathrm{C} 3, \mathrm{C} 4)$ and the known transmitted spectra of the TS S $(\mathrm{C} 1, \mathrm{C} 2, \mathrm{C} 3, \mathrm{C} 4)$, the receiver calculates the zero-forcing $(\mathrm{ZF})$ channel estimation $\mathbf{W}(f)$ [2]. The performance of the channel estimation is dependent on the correlation properties of the training sequence, the length, the shape and whether a GI is employed. In the following, we refer to the Nulling TS if C2 and C3 are zero, which is detrimental for the modulator and the gain control due to the varying power level. However, a low-complexity estimation by simply processing $\left[\mathrm{W}_{11}, \quad \mathrm{~W}_{12}\right]=[\mathrm{R}(\mathrm{C} 1) / \mathrm{S}(\mathrm{C} 1), \mathrm{R}(\mathrm{C} 3) / \mathrm{S}(\mathrm{C} 1)]$ and $\left[\mathrm{W}{ }_{21}\right.$, $\left.\mathrm{W}_{22}\right]=[\mathrm{R}(\mathrm{C} 2) / \mathrm{S}(\mathrm{C} 4), \mathrm{R}(\mathrm{C} 3) / \mathrm{S}(\mathrm{C} 4)]$ can be obtained. We refer to Diverse by choosing orthogonal sequences $\mathrm{C} 1, \mathrm{C} 2$, $\mathrm{C} 3, \mathrm{C} 4$, where solving the equations to estimate $\mathbf{W}(f)$ becomes more complex [2]. Each sequence C1, C2, C3, C4 is cyclic. Each GI continues the adjacent sequence.

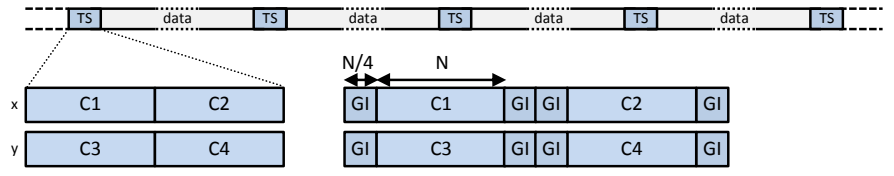

Fig 1. Training sequences sent in the transmission burst of a $2 \times 2$ MIMO system.

\begin{tabular}{lll}
\hline \hline Impairment & Distribution & \multicolumn{1}{c}{ Value range } \\
\hline PMD & Maxwellian & Mean $25 \mathrm{ps}$ \\
PDL & linear & {$[0: 10] \mathrm{dB}$} \\
CD & linear & {$[-500: 500] \mathrm{ps} / \mathrm{nm}$} \\
Pol.phase & linear & {$[0: 2 \pi] \mathrm{rad}$} \\
Pol.angle & linear & {$[0: 2 \pi] \mathrm{rad}$} \\
OSNR & constant & $14 \mathrm{~dB}$
\end{tabular}

Table 1. Parameter Range and Distribution for Channel.

\section{Estimation performance}

We demonstrate CD and DGD parameter estimation based on the Nulling and the Diverse training scheme, each with and without GI, for simulated $112 \mathrm{Gbit} / \mathrm{s}$ PDM-QPSK transmission over a wide range of random channel parameters chosen from Table 1. At the receiver, white Gaussian noise is loaded onto the signal, followed by an optical Gaussian band-pass filter $\left(2^{\text {nd }}\right.$-order, double-sided $\left.35 \mathrm{GHz}\right)$, the polarization-diverse $90^{\circ}$-hybrid and an electrical Bessel filter $\left(5^{\text {th }}\right.$-order, $\left.19 \mathrm{GHz}\right)$. Finally, an ADC stage digitizes the received signal at 2 samples per symbol. Averaging over 1 to 10 channel estimations has been applied before the single channel parameters have been separated from the resulting channel estimation $\mathbf{W}(f)$. The residual CD is estimated from the quadratic fit of the resulting parabolic phase function [4], and the DGD estimation was achieved by averaging over the central taps (12.5\% of all taps) of the DGD spectrum [5]. For each scheme, the standard deviation of the estimation error is evaluated based on 1000 random channel trials. The length of the CAZAC sequence block $N$ was chosen to be equal to 16 or 64 symbols. A GI of length N/4 was added at the head and at the tail of each sequence according to Fig. 1. 


\section{SPTuC3.pdf}
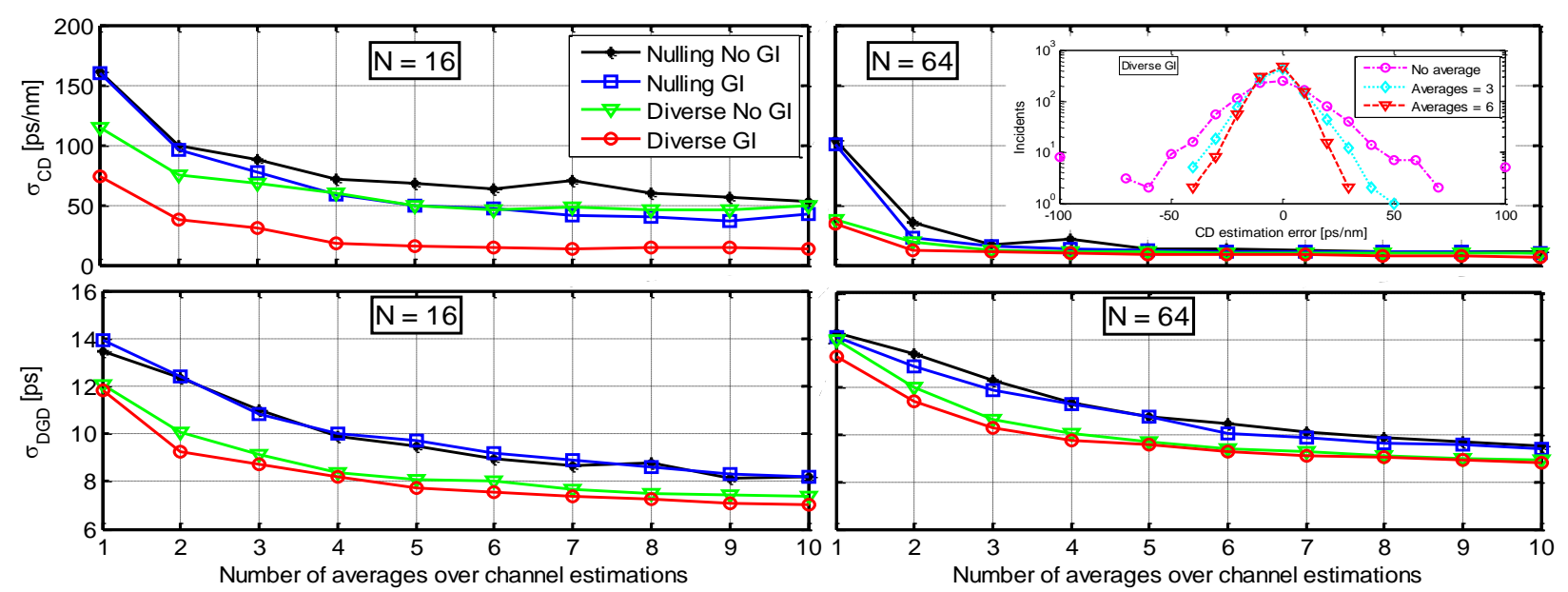

Fig.2. Standard deviation of CD and DGD estimation error for different numbers of channel averages with TS of $N=16$ and $N=64$ symbols.

The results of the evaluation are shown in Fig.2. The Diverse method performs better than the Nulling method with a faster convergence reaching the optimum channel estimation. In particular, the DGD estimation benefits from the possible polarization coupling if both polarizations carry orthogonal signals. The GI, which fully covers the channel memory induced by CD (pulse spread over 3.4 symbols for $500 \mathrm{ps} / \mathrm{nm}$ ), absorbs interference between a training block with the adjacent TS or with data blocks. This leads to a clear performance improvement of the CD estimation with short training sequences. For DGD with a relatively small channel memory (pulse spread rarely exceeds 2 symbols), the GI does not show significant improvement.

Using the Diverse method with GI and a length $N=16$, no significant improvement is seen after only 4 channel averages with an standard deviation of the estimation error of $18 \mathrm{ps} / \mathrm{nm}$ and $8 \mathrm{ps}$ for CD and DGD estimation respectively. In this case, a total number of only 192 symbols is sufficient for a reliable CD and DGD monitoring. For $N=64$, the CD estimation converges after only 2 averages, with a total of 320 symbols, which results from the better resolution of the received signal spectra $\mathrm{R}(\mathrm{C})$. As shown in the inset of Fig. 2, top right, for the Diverse method with GI, the histogram of the CD estimation error proves a zero mean value with a standard deviation of 35 $\mathrm{ps} / \mathrm{nm}$ when no average is considered and only $8 \mathrm{ps} / \mathrm{nm}$ when 6 channel averages are applied. After only 3 channel averages, no escape estimations can be observed with a worst-case error of $50 \mathrm{ps} / \mathrm{nm}$. It should be noted that the best NDA CD estimation requires a minimum of 4096 symbols [5].

If the length of the TS is much larger than the channel memory length, as it is the case for $N=64$, the GI does not play an important role for the CD and DGD estimation. However, unexpectedly the DGD estimation performance is not improved for $N=64$ compared to $N=16$, as the DGD estimator has been only optimized for low number of symbols. With optimized parameters, we expect an equal or better DGD estimation for $N=64$.

\section{Conclusions}

Fast, reliable and precise CD and DGD estimation based on FD DA channel estimation has been demonstrated in presence of combined linear channel impairments. Based on a total number of only 192 symbols, a standard deviation of the CD and DGD estimation error of $18 \mathrm{ps} / \mathrm{nm}$ and $8 \mathrm{ps}$ respectively has been obtained. This is the least number of symbols for the best estimation performance to our knowledge.

\section{Acknowledgement}

The research leading to these results has received funding from the European Community's Seventh Framework Programme [FP7/2007-2013] under grant agreement $\mathrm{n}^{\circ} 258644$, CHRON project.

\section{References}

[1] C.R.S. Fludger, T. Duthel, D. Van Den Borne, et al., "Coherent Equalization and POLMUX-RZ-DQPSK for Robust 100-GE Transmission " J. of Lightwave Technol., vol. 26, no.1, pp. 64-72, Jan. 2008.

[2] M. Kuschnerov, M. Chouayakh, K. Piyawanno, et al., "Data-Aided Versus Blind Single-Carrier Coherent Receivers," IEEE Photonics Journal, vol. 2, no. 3, pp. 386-403, June 2010.

[3] Chan, Calvin C. K. “Optical Performance Monitoring - Advanced Techniques for Next-Generation Photonic Networks.” Elsevier, 2010.

[4] F. N. Hauske, M. Kuschnerov, B. Spinnler, and B. Lankl, "Optical Performance Monitoring in Digital Coherent Receivers," J. Lightwave Technol. 27, 3623-3631 (2009).

[5] F. N. Hauske, C. Xie, Z. P. Zhang, C. Li, L. Li, and Q. Xiong, "Frequency Domain Chromatic Dispersion Estimation," in OFC 2011, paper JThA11. 